\title{
Artritis infecciosa y su relación con la articulación temporomandibular
}

\section{Infectious arthritis and its relationship with the temporomandibular joint}

\author{
Iturriaga Wilder V*, Bornhardt Suazo T*, Fuentes Nawrath J*, \\ Fuentes Fernández R*, Raposo Castillo A**
}

\section{RESUMEN}

La artritis infecciosa (AI) es, como su nombre lo indica, la infección de una articulación del cuerpo producida por un agente que puede ser bacteriano, viral o fúngico (Bluestone, 1980; García \& Picazo, 1996). Esta patología es poco común y poco documentada cuando afecta la articulación temporomandibular, existiendo sólo reporte de casos. Por lo anterior, muchas veces pasa desapercibida por distintos profesionales del área de la salud. El diagnóstico de la AI mediante radiología no aporta gran información en etapas tempranas de la patología (Lavy, 2007; Visser E Tupper, 2009). Un método de diagnóstico utilizado en grandes articulaciones del cuerpo es el cultivo de líquido sinovial (Lavy; Visser $\mathcal{E}$ Tupper), examen complejo de realizar en la articulación temporomandibular dado su tamaño y pequeña cantidad de fluido sinovial, siendo así el diagnóstico de Al en gran medida clínico, y en el caso de la articulación temporomandibular es aún más importante la experticia y conocimientos del clínico. El tratamiento se debe basar en la eliminación del agente causal mediante farmacoterapia orientada a la eliminación de éste (Lavy; Visser $\&$ Tupper). La artritis infecciosa por sus características de avance rápido, agresivo y degenerativo, debe ser considerada como un posible diagnóstico en la articulación temporomandibular, por lo que esta revisión bibliográfica presenta información acabada sobre la epidemiología, etiopatogenia, diagnóstico y tratamiento de dicha patología existente en diversas bases de datos y literatura contemporánea.

Palabras clave: Articulación temporomandibular, trastornos temporomandibulares, artritis infecciosa, artritis reactiva.

\section{SUMMARY}

Infectious arthritis (IA) is, as its name implies, infection of a joint in the body caused by an agent that can be bacterial, viral or fungal (Bluestone, 1980, Garcia \& Picazo, 1996). This condition is uncommon and poorly documented when it affects the temporomandibular joint (TMJ), and there are only case reports. Due to this is often unnoticed by other professionals in the field of health. The diagnosis of radiologically IA does not provide much information at early stages of pathology (Lavy, 2007, Visser $\mathcal{E}$ Tupper, 2009). A diagnostic method used in large joints of the body is the cultivation of synovial fluid (Lavy, Visser $\mathcal{E}$ Tupper), perform complex examination of the TMJ given its size and small amount of synovial fluid, making it the diagnosis of IA largely Clinically, and in the case of TMJ more importantly the expertise and clinical knowledge. The treatment should be based on the elimination of the agent through pharmacotherapy aimed at the elimination of it (Lavy, Visser $E$ Tupper). Infectious arthritis due to its characteristics of fast-forward, aggressive and degenerative, should be considered as a possible diagnosis in the TMJ, so this literature review provides completed information on the epidemiology, etiology, diagnosis and treatment of this pathology exists in different databases and contemporary literature.

* Departamento de Odontología Integral. Universidad de La Frontera. Temuco, Chile.

** Práctica privada. Temuco, Chile. 
Key words: Temporomandibular joint, temporomandibular joint disorders, arthritis Infectious, arthritis reactive.

Fecha de recepción: 15 de mayo de 2010.

Aceptado para publicación: 10 de julio de 2010.

Iturriaga Wilder V, Bornhardt Suazo T, Fuentes Nawrath J, Fuentes Fernández R, Raposo Castillo A. Artritis infecciosa y su relación con la articulación temporomandibular. Av. Odontoestomatol 2012; 28 (1): 25-32.

\section{INTRODUCCIÓN}

La palabra artritis actualmente significa inflamación articular (1), es usada para describir más de 100 enfermedades y condiciones que afectan las articulaciones, los tejidos que rodean la articulación y otros tejidos conectivos (1). La artritis infecciosa (AI), también llamada séptica, piógena, supurativa, purulenta o piartrosis, es una inflamación de la articulación causada por un microorganismo determinado (2). La artritis infecciosa no sólo puede conducir a la rápida destrucción del cartílago hialino o fibrocartílago y a la pérdida irreversible de la función articular $(3,4)$, sino que puede ser mortal, especialmente cuando afecta a los recién nacidos (5) y pacientes con comorbilidad (6).

La artritis infecciosa de la Articulación Temporomandibular (ATM) es un cuadro que raramente la afecta (7), o se encuentra pocas veces descrito en la literatura. La ATM es una articulación sinovial, bicondílea y diartrósica (8-10) con dos características propias: las superficies articulares están cubiertas por fibrocartílago, más resistente que el cartílago hialino y es la única articulación humana que tiene un punto de cierre rígido, los dientes (9).

La ATM es bastante compleja ya que involucra dos articulaciones sinoviales separadas que funcionan al unísono, además posee un disco interarticular, que suple las diferencias morfológicas articulares y divide la cavidad articular en compartimento superior e inferior (9). La cápsula articular, los ligamentos y los músculos permiten una actividad funcional compleja y movimientos multidireccionales suaves, importantes para realizar la masticación y fonación entre otras funciones (8).
Todo esto le ofrece muchas desventajas al momento de presentarse alguna patología, como en éste caso una artritis infecciosa.

Cuando la ATM se ve afectada por una AI generalmente proviene directamente de una infección adyacente de origen dental, ótico o de la glándula parótida $(7-9,11,12)$ o es parte de una enfermedad sistémica como la gonorrea, sífilis, tuberculosis o síndrome de Lyme $(8,9)$. Además puede presentarse por vía hematógena tras un traumatismo o por vía directa por herida penetrante $(8,9)$. Ocurre más frecuentemente en ATMs que presentaban anteriormente otro tipo de patologías y produce secuelas articulares graves o disfunción (11).

\section{EPIDEMIOLOGÍA}

La AI es una enfermedad poco frecuente en la ATM, no se encontraron datos epidemiológicos específicos para esta articulación, existiendo sólo reportes de casos disponibles. Dentro de la información disponible de AI y ATM la más común es AI de origen bacteriano, siendo la de origen viral y fúngica muy rara en dicha articulación. Por lo anteriormente mencionado los datos a continuación son de AI en general, excepto cuando se especifica que se refiere a la ATM.

La AI puede ocurrir a cualquier edad siendo los niños más susceptibles que los adultos y requieren tratamiento rápido (13), en neonatos la artritis infecciosa puede producir deformaciones esqueletales permanentes (14).

La articulación más comúnmente afectada por AI es la de la rodilla $(5,15-19)$. Es más frecuente en hom- 
bres que en mujeres (5, 20, 21). Ogunlusini (2006) reportó que los hombres tenían una relación de 2.9:1 respecto a las mujeres en la población de Nigeria (5). En contraste, algunos estudios como el realizado por Kaandorp (1997) en Ámsterdam (22) o el de Eder (2005) en Israel (16), que no encontraron diferencias significativas entre hombres y mujeres $(16,22)$.

Se estima que la incidencia de la AI bacteriana es de 2 a 6 casos por 100.000 habitantes al año (11). Un estudio realizado en Islandia entre 1990 a 2002 por Geirsson (2008) reportó una incidencia de 7.1 casos por cada 100.000 habitantes (3). Otro estudio realizado en Amsterdam por Kaandorp (1997) señala una incidencia de 5.7 casos por cada 100.000 habitantes (22). La incidencia de AI en pacientes con artritis reumatoidea es de 20 a 38 casos por 100.000 habitantes (23) y la incidencia en pacientes con prótesis articulares es de 40 a 68 por 100.000 habitantes (24).

En cuanto a la edad, el mayor número de casos se ubica en el tramo de 0 a 14 años seguido del tramo de 65 años y más (16). Otros estudios también indican una mayor prevalencia en los extremos de la vida, cambiando el antiguo patrón de distribución por edad, que señalaba que era una enfermedad más bien de niños $(3,15,22)$.

En cuanto a AI viral un reciente estudio realizado en Francia por Zerrak et al., 2005, obtuvieron que de 322 pacientes con poliartralgias y artritis infecciosa de menos de un año de evolución, en sólo 2 casos $(0.6 \%)$ la artritis era atribuida directamente por una infección viral (25). Resultados similares se obtuvieron en 60 pacientes terminales con $\mathrm{AI}$, de los cuales sólo en el 3\% existía evidencia de infección reciente con Parvovirus B19 (25).

\section{ETIOPATOGENIA}

La AI puede ser causada de forma directa o indirecta por cualquier patógeno, bacteriano, viral y por último fúngico $(4,6,10,26)$. Lo más frecuente en la ATM es la causa adyacente de origen dental, parotídeo u ótico (9). Además puede producir por diseminación vía hematógena de una infección en otro lu- gar del cuerpo $(4,21)$. Esto puede deberse a una infección sistémica, comúnmente, gonorrea, sífilis, tuberculosis o enfermedad de Lyme (6, 7, 9, 26). En ocasiones raras puede ser producto de una artrocentesis o cirugía (4). Por otro lado la presencia de bacterias en la articulación no necesariamente causa una artritis infecciosa, deben existir una serie de otros factores para que ésta se lleve a cabo, como lo son enfermedades graves concomitantes, cirrosis, fallas renales o diabetes. En conclusión la combinación entre una enfermedad crónica y una infección aguda (21).

En EEUU el agente causal más frecuente de AI bacteriana es Neisseria gonorrhoeae $(6,26)$. Se describe que, sin contar las artritis infecciosas gonorreicas, en adultos aproximadamente tres cuartas partes de ellas corresponden a cocáceas gram $(+)$, como Staphylococcus y Streptococcus (27).

En caso de artritis virales, los agentes más frecuentes son: Parvovirus B19, virus de la hepatitis B y C, virus de la rubéola y su vacuna, alfavirus y virus de la inmunodeficiencia humana (VIH) (25).

Los pacientes de alto riesgo para presentar una AI viral son por ejemplo, pacientes que se realizaron transfusiones sanguíneas antes de 1992, personas con múltiples parejas sexuales, usuarios de drogas de inyección intravenosa, trabajadores del área de la salud que utilizan agujas o que están expuestos a sangre frecuentemente e inmigrantes o viajeros de zonas endémicas de infección por alfavirus (25).

\section{FISIOPATOLOGÍA}

En la AI por causa bacteriana, las bacterias se multiplican en la sinovia y se produce la llegada de células del sistema inmune, con la presencia de inflamación, rubor, calor local e impotencia funcional $(4,6$, $7,21,26)$. En algunos casos se ven síntomas generales como fiebre y escalofríos $(7,19,21)$. Finalmente se produce exudación de células polimorfonucleares al espacio articular y aumento de la presión articular. Esto produce que los leucocitos polimorfonucleares se activen por la presencia bacteriana y produzcan colagenasas y proteasas las cuales son las responsables de la degradación del cartílago ar- 
ticular y eventual pérdida de la integridad. Por otro lado también se producen enzimas proteolíticas por parte de las bacterias las cuales de igual forma destruyen los mucopolisacáridos (21).

En casos de infección viral existen tres tipos de cuadros, el cuadro agudo; el cuadro latente, como el virus herpes y el cuadro crónico como el VIH y el virus de la hepatitis C (25).

En casos de AI virales se produce por la formación de complejos inmune o virus latentes que producen una desregulación inmune (25) lo cual tiene efectos líticos en los tejidos articulares e inducción de citoquinas inflamatorias (25). Algunos virus pueden producir respuestas autoinmunes e inflamación por mecanismos como el mimetismo molecular o el epítope de propagación (25). En la mayoría de los casos de infección viral el mecanismo es poco conocido (25).

\section{DIAGNÓSTICO}

El diagnóstico de $\mathrm{Al}$ en cualquier articulación del cuerpo, es esencialmente clínico (21). Se presenta con dolor local unilateral, hipersensibilidad, enrojecimiento, e inflamación de la articulación, acompañada por fiebre, escalofríos y sudores, hallazgos que dependen de la infección específica (9). El dolor es una artralgia inflamatoria en reposo pero que se acentúa con la función. No suele haber limitación de los movimientos. La posición más cómoda esta representada por la posición en que la articulación alcanza un máximo volumen, es decir donde se encuentre el mínimo de presión (21). En el caso de la ATM, puede modificarse la oclusión (7), producirse una mordida abierta anterior si ha existido osteólisis de las superficies articulares o mordida abierta posterior si existe un edema intraarticular (28).

La clínica no va siempre asociada a las alteraciones radiológicas. El uso de radiografías en etapas tempranas no es muy útil, ya que no se aprecian cambios en los primeros 10 días $(19,21)$.

En este caso puede utilizarse cintigrafía ósea la cual ha mostrado una sensibilidad en un estudio de Coll (2009) de hasta un $87.5 \%$ y una especificidad de un
$75 \%$ o puede utilizarse resonancia nuclear magnética (RNM) donde puede aparecer una separación de superficies articulares por aumento de partes blandas (29), al igual que la utilización de ultrasonido y tomografía axial computarizada (TAC) donde se aprecia el aumento de espacio (21).

No existe un examen de recuento de células blancas, tiempo de sedimentación de eritrocitos, o una valoración de proteína C-reactiva que sea sensible o específico para realizar un diagnóstico de AI (19). El diagnóstico definitivo es dado por un cultivo bacteriológico a través de un examen de líquido sinovial por artrocentesis $(19,21)$, lo cual además puede dar una guía en la selección del antibiótico a utilizar. La única contraindicación de este procedimiento es una Infección periarticular (21).

El recuento de células blancas en el líquido sinovial es variable y va desde 25.000 a 250.000 células por mililitro, siendo la mayoría de éstas (90\%) polimorfonucleares (21). Los niveles de ácido láctico se ven aumentados, excepto en una infección por gonococos (21).

El pronóstico depende de la gravedad, va desde leves secuelas hasta la pérdida de la articulación, pasando por artrosis y anquilosis tanto fibrosa como ósea. El tratamiento es según el agente causal.

\section{TRATAMIENTO}

La AI en cualquier articulación del cuerpo, es una condición seria indistintamente del lugar del mundo. El potencial de que las complicaciones sean mayores hace del diagnóstico y tratamiento una acción de urgencia (21). Los principios generales de tratamiento para las AI pasan por erradicar la infección y proteger la articulación (19), limitando los movimientos, a los que no sean dolorosos, los ejercicios de movimientos activos y pasivos no dolorosos, AINES y calor profundo (28). En el caso específico de la ATM se debe recurrir a férulas oclusales, asociadas a los cuidados generales antes mencionados (28).

En caso de ser bacteriana debe ser tratada con antibióticos y en caso necesario, con desbridamiento quirúrgico $(21,28)$. En el caso más especifico que sea bacteriano y de siembra hematógena debe hos- 
pitalizarse y administrar al paciente antibiótico vía endovenosa (EV) seguido de antibióticos por vía oral en altas dosis. En el caso de no ser siembra hematógena la hospitalización no es necesaria.

Los antibióticos de elección son los de tercera generación, como cefalosporina o vancomicina. Para los pacientes alérgicos a cefalosporina se puede utilizar fluoroquinolonas, como levofloxacin o ciprofloxacin (19). En la tabla 1 se presenta un resumen de la antibioterapia recomendada para tratar la AI de cualquier articulación dependiendo de cada bacteria (26).
La literatura es controversial con el tiempo de duración de la terapia EV y el tipo de antibiótico a utilizar $(19,21)$. La mayoría de los protocolos recomiendan 2 a 4 semanas, seguido de 2 a 6 semanas de tratamiento oral (19).

En este plano se discute el uso de tratamiento farmacológico versus el tratamiento quirúrgico (19). El manejo quirúrgico llamado artrocentesis consiste en el lavado de la cavidad articular superior de la ATM a través dos agujas transcutáneas de entrada y salida $(19,30)$. No existen estudios randomizados que eva-

\section{TABLA 1.- ANTIBIOTERAPIA ESPECÍFICA RECOMENDADA EN CUADROS DE ARTRITIS INFECCIOSA BACTERIANA (HARRIS ET AL, 2007)}

\begin{tabular}{|c|c|c|c|}
\hline $\begin{array}{l}\text { Tinción gram del } \\
\text { líquido sinovia }\end{array}$ & Microorganismo & Antibiótico & Dosis \\
\hline \multirow[t]{2}{*}{$\begin{array}{l}\text { Cocos gram } \\
\text { positivos (grupos) }\end{array}$} & $\begin{array}{l}\text { Staphylococus Aureus } \\
\text { (sensible a la meticilina) }\end{array}$ & $\begin{array}{l}\text { - Nafcilina/oxacilina } \\
\text { - Cefazolina }\end{array}$ & $\begin{array}{l}2 \mathrm{gr} \text { iv c/4 h } \\
1-2 \mathrm{gr} \text { iv c/ } 8 \mathrm{~h}\end{array}$ \\
\hline & $\begin{array}{l}\text { Staphylococus Aureus } \\
\text { (resistente a la } \\
\text { meticilina) }\end{array}$ & $\begin{array}{l}\text { - Vancomicina, clindamicina o } \\
\text { linezolid }\end{array}$ & $\begin{array}{l}1 \mathrm{gr} \text { iv c/ } 12 \mathrm{~h} \\
900 \mathrm{mg} \text { iv c/8 h } \\
600 \mathrm{mg} \text { iv c/12 h }\end{array}$ \\
\hline $\begin{array}{l}\text { Cocos gran } \\
\text { positivos (cadenas) }\end{array}$ & $\begin{array}{l}\text { Especies de } \\
\text { Streptococus }\end{array}$ & $\begin{array}{l}\text { - Nafzalina } \\
\text { - Penicilina } \\
\text { - Cefazolina }\end{array}$ & $\begin{array}{l}2 \mathrm{gr} \text { iv } \mathrm{c} / 4 \mathrm{~h} \\
2 \mathrm{mill} \text { ui iv } \mathrm{c} / 4 \mathrm{~h} \\
1-2 \mathrm{gr} \text { iv } \mathrm{c} / 8 \mathrm{~h}\end{array}$ \\
\hline $\begin{array}{l}\text { Diplococos gram } \\
\text { negativos }\end{array}$ & Neisseria Gonorreae & $\begin{array}{l}\text { - Ceftriaxona } \\
\text { - Cefotaxima } \\
\text { - Ciprofloxacino }\end{array}$ & $\begin{array}{l}2 \mathrm{gr} \text { iv c/ } 24 \mathrm{~h} \\
1 \mathrm{gr} \text { iv c/ } 8 \mathrm{~h} \\
400 \mathrm{mg} \text { iv c/12 h }\end{array}$ \\
\hline \multirow[t]{2}{*}{$\begin{array}{l}\text { Bacilos gram } \\
\text { negativos }\end{array}$} & Enterobacteráceas & $\begin{array}{l}\text { - Ceftriaxona } \\
\text { - Cefotaxima }\end{array}$ & $\begin{array}{l}2 \mathrm{gr} \text { iv } \mathrm{c} / 24 \mathrm{~h} \\
1 \mathrm{gr} \text { iv } \mathrm{c} / 8 \mathrm{~h}\end{array}$ \\
\hline & $\begin{array}{l}\text { Especies de } \\
\text { seudomonas }\end{array}$ & $\begin{array}{l}\text { - Cefepime } \\
\text { - Piperacilina } \\
\text { - Imipenem + gentamicina }\end{array}$ & $\begin{array}{l}2 \mathrm{gr} \mathrm{iv} \mathrm{c} / 12 \mathrm{~h} \\
3 \mathrm{gr} \text { iv c/6 h } \\
500 \mathrm{mg} \text { iv c/6 h }+ \\
7 \mathrm{mg} / \mathrm{kg} \text { iv c/24 h }\end{array}$ \\
\hline $\begin{array}{l}\text { Infección } \\
\text { polimicrobiana }\end{array}$ & $\begin{array}{l}\text { S. aureus, } \\
\text { streptococcus, bacilos } \\
\text { gran negativos }\end{array}$ & $\begin{array}{l}\text { - Nafcilina/oxacilina + } \\
\text { ceftriaxona } \\
\text { - Cefotoxamina } \\
\text { - Ciprofloxacino } \\
\text { - Vancomicina + cefalosporina } \\
\text { (alérgico a PNC) }\end{array}$ & $\begin{array}{l}2 \mathrm{gr} \mathrm{iv} \mathrm{c} / 4 \mathrm{~h}+2 \mathrm{gr} \\
\text { iv c/24 h } \\
2 \mathrm{gr} \text { iv c/8 h } \\
400 \mathrm{mg} \text { iv c/12 h }\end{array}$ \\
\hline
\end{tabular}


lúen el drenaje articular comparado con el tratamiento sin drenaje articular (19).

Cabo (2009) en su trabajo cita a Yang el cual señala que la AI aguda de la articulación temporomandibular puede ser tratada por medio de la artrocentesis de baja presión en combinación con terapia antimicrobiana y reposo mandibular, pudiendo estar incluido el drenaje submandibular según el caso, todo ello con resultados satisfactorios (30). Los corticoides deben emplearse con precaución, porque pueden empeorar la degeneración articular (28).

Por otro lado Lavy (2007) hace referencia a Smith el cual demostró que la destrucción del cartílago comienza a ocurrir a las 8 horas post infección. Por lo que la administración de antibióticos debe ser lo antes posible para disminuir el proceso, ya que incluso la terapia EV comienza su efecto a las $24 \mathrm{~h}$ lo que significa una destrucción significativa de glucosaminoglicanos y colágeno (21).

En el caso de ser un virus, raramente se trata con antivirales específicos ya que la infección generalmente es autolimitante y asociada a cuadros generales también autolimitantes $(6,10,26)$.

En el caso de las AI por agente fúngico, el tratamiento se basa al igual que en las AI bacterianas, a la eliminación del agente causal mediante farmacoterapia o desbridamiento quirúrgico. Cabe señalar que la $\mathrm{AI}$ de origen fúngico es mucho más prevalente en articulaciones protésicas que en naturales y en pacientes inmunosuprimidos $(26,31)$

\section{DISCUSIÓN Y CONCLUSIONES}

La AI si bien es una patología poco frecuente en la ATM, es necesario saber reconocerla y realizar un correcto diagnóstico diferencial por ser ésta muy agresiva y de secuelas degenerativas.

La falta de información disponible nos habla de una necesidad de mayor investigación, ya que datos epidemiológicos y estudios clínicos apuntan a articulaciones de mayor envergadura del cuerpo (rodilla, cadera) pero es importante no olvidar articulaciones como la ATM, ya que su mal funcionamiento o pér- dida de función afecta directamente funciones vitales biosicosociales, como la masticación, deglución y fonoarticulación. Se dice que la AI en ATM es rara, pero creemos que faltan estudios e investigación para afirmar esto ya que quizás no es tan poco frecuente sino que es poco pesquisada y se confundiría con sus secuelas.

El análisis de líquido sinovial mediante punción y estudio de laboratorio, que otorga una información irrefutable en articulaciones mayores, se torna difícil, ya que la técnica es compleja por el tamaño de la articulación, el complicado acceso a ella y la cantidad de fluido sinovial.

Dado lo anteriormente mencionado se requiere realizar una mayor investigación, ya que el diagnóstico debiera realizarse clínicamente y realizar un diagnóstico diferencial con gran cantidad de patologías que por cercanía aumentan el riesgo de una AI de la ATM.

La AI es una enfermedad que puede surgir como única o mas comúnmente secundaria a otras patologías, es por esto que es importante que los profesionales de la salud conozcan esta enfermedad y sepan cuando derivar a un grupo de especialistas los cuales pueden ayudar a detener la enfermedad y/o a rehabilitar al paciente, el cual además de la imposibilidad funcional debe soportar cuadros muy dolorosos y problemas de autoestima y sociales. Por ésto que éste tipo de pacientes debe tratarse desde un punto de vista interdisciplinario con un grupo de especialistas médicos y odontólogos.

\section{BIBLIOGRAFÍA}

1. Bluestone R. Rheumatology. Houghton Mifflin Professional Publishers: Boston, United States; 1980.

2. García J, Picazo J. Microbiologia médica. Haurcourt Brace: Madrid, España; 1996.

3. Geirsson ÁJ, Statkevicius S, Víkingsson A. Septic arthritis in Iceland 1990-2002: increasing incidence due to iatrogenic infections. Ann Rheum Dis 2008;67:638-43. 
4. Shirtliff ME, Mader JT. Acute septic arthritis. Clin Microbiol Rev 2002;15 (Pt: 4):527-44.

5. Ogunlusini J, Olunlusini L, Oginni L, Olowookere J. Septic arthritis in a nigerian tertiary hospital. lowa Orthop J 2006;26: 45-7.

6. Sociedad Española de Reumatología. Manual SER de las enfermedades reumáticas. $5^{\mathrm{a}}$ ed. Panamericana: España; 2008.

7. Saðlam S, Ayhan-Ardic F. Temporomandibular disorders seen in rheumatology practices: a review. Rheumatol Int 2006;26:781-7.

8. Concha G. Imágenes por resonancia magnética de la articulación temporomandibular. Revista HCUCh 2007;18:121-30.

9. Morlá R. Articulación temporomandibular: 1-Anatomía y patología más frecuente. Seminarios de la Fundación Española de Reumatología 2004; 5(Pt 5):229-39.

10. Okeson J. Tratamiento de oclusión y afecciones temporomandibulares. $6^{a}$ ed. Elsevier: Barcelona, España; 2008.

11. Casar JC, Gutierrez JL, Infante P, Torres D. Journal of oral and maxillofacial surgery. Revisión de noviembre 2002 a febrero 2003. Revista Secib On Line 2004;2:1-13.

12. Sembronio S, Albiero A, Robiony M, Costa F, Toro C, Polito M. Septic arthritis of the temporomandibular joint successfully treated with arthroscopic lysis and lavage: case report and review of the literature. Oral Surg Oral Med Oral Pathol Oral Radiol Endod 2007;103(2):1-6.

13. Salzbach R. Pediatric septic arthritis. AORN J 1999;70(Pt 6):988, 991-1002.

14. Bos C, Mol L, Obermann W, Tjin a Ton E. Late sequelae of neonatal septic arthritis of the shoulder. J Bone Joint Surg Br 1998; 80(Pt 4):645-50.

15. Cooper C, Cawley M. Bacterial arthritis in an English health district: a 10 year review. Ann Rheum Dis 1986; 45:458-63.
16. Eder L, Zisman D, Rozenbaum M, Rosner I. Clinical features and aetiology of septic arthritis in northern Israel. Rheumatology 2005;44:1559-63.

17. Morgan D, Fisher D, Merianos A, Currie B. An 18-year clinical review of septic arthritis from tropical Australia. Epidemiol Infect 1996;117(Pt 3): 423-8.

18. Razak M, Nasiruddin J. An epidemiological study of septic arthritis in Kuala Lumpur Hospital. Med J Malaysia 1998; 53 Suppl A:86-94.

19. Visser S, Tupper J. Septic until proven otherwise Approach to and treatment of the septic joint in adult patients. Canadian Family Physician, Le Médecin de famille canadien 2009;55:374-5.

20. Del Val N, Erausquin C, Blanco R, Pinillos V, Martínez V, Rodríguez V. Study of 112 patients with septic arthritis caused by pyogenic organisms and fungi: changes in the clinical spectrum during the last two decades. Rev Clin Esp 1997; 197(Pt 8):540-4.

21. Lavy C. Septic arthritis in Western and subSaharan African children - a review. International Orthopaedics (SICOT) 2007; 31:137-144.

22. Kaandorp C, Dinant H, van de Laar M, Moens H, Prins A, Dijkmans B. Incidence and source of native and prosthetic joint infection: a community based prospective survey. Ann Rheum Dis 1997; 56:470-5.

23. Mitchell W, Brooks P, Stevenson R, Buchanan W. Septic arthritis in patients with rheumatoid disease: a still underdiagnosed complication. J Rheumatol 1976;3:124-33.

24. Poss R, Thornhill T, Ewald F, Thomas W, Batte N, Sledge $\mathrm{C}$. Factors influencing the incidence and outcome of infection following total joint arthroplasty. Clin Orthop 1984;182:117-26.

25. Vassilopoulos D, Calabrese LH. Review Virally associated arthritis 2008: clinical, epidemiologic, and pathophysiologic considerations. Arthritis Research E Therapy 2008;10:215. 
26. Harris D, Budd R, Firestein G, Ruddy S, Sergent J. Kelley Tratado de Reumatología. Vol. II $7^{\text {a }}$ ed. Elsevier: Madrid, España; 2005.

27. Perez C, Rojas A, Baudrand R, Garcia P. Artritis séptica por Psychrobacter phenylpyruvicus: Primer caso clínico y revisión de la literatura. Rev. chil infectol [online]. 2002;19(Pt 2):96-100.

28. Valmaseda E, Escoda CG. Diagnóstico y tratamiento de la patología de la articulación temporomandibular. ORL- DIPS 2002; 29(Pt 2):55-70.

29. Coll C, Cifras J, Massardo T, Moya H. Cintigrafía ósea trifásica con tc-99mmdp en el diagnóstico y manejo de infecciones osteoarticulares agudas en niños. Rev chil Radiol 2009;8(Pt 2):83-8.

30. Cabo R, Grau L, Ileana B, Lorenzo A, Perez O. Generalidades del manejo quirúrgico de los tras- tornos temporomandibulares con técnicas poco invasivas. Rev haban cienc méd 2009;8(Pt 4): 0-0.

31. Gil G, Foster C, Neira O, Palma S, Basualdo J, Heredia C et al. Artritis por Cryptococcus neoformans en un adulto mayor: Presentación de un caso y revisión. Rev chil infectol 2006; 23(Pt 4):330-5.

\section{CORRESPONDENCIA}

Dra. Iturriaga W. V.

Departamento de Odontología Integral Universidad de La Frontera

Manuel Montt, 112

Temuco, Chile

E-mail: Iturriaga.v@gmail.com 